\title{
The Evidence for a Linkage Isomerism in Solid Cupric Ferricyanide
}

\author{
K. Tennakone \\ Department of Physics, University of Ruhuna, Matara, Sri Lanka
}

(Date of receipt: 23 May 1984)

(Date of acceptance: 28 December 1984)

\begin{abstract}
Experimental evidence is presented to show that solid cupric ferricyanide undergoes a structural transition when bonded interstitial water is removed. It is suggested that this transition is caused by a linkage isomerism where the co-ordination of $\mathrm{C}$ to $\mathrm{Fe}^{2+}$ and $\mathrm{N}$ to $\mathrm{Cu}++$ in $\mathrm{CN}^{-}$is reversed.
\end{abstract}

\section{Introduction}

Prussian blue type compounds, i.e. the ferrocyanides. and ferricyanides of heavy metals form a class of crystalline solids with fascinating structure ${ }^{5,16}$ They have face-centred cubic arrangements of metal cations at the corners of unit cubes linked by cyanide ions placed along the edges. ${ }^{5,{ }^{1} 6}$ In ferrocyanides the carbon atom of $\mathrm{CN}^{-}$is co-ordinated to $\mathrm{Fe}^{2+}$ and the nitrogen atom is co-ordinated to the other metal ion. Ferricyanides have the same type of bondings 5,16 with $\mathrm{Fe}^{2+}$ replaced by $\mathrm{Fe}^{3+}$. A remarkable property arising from this structure, is that the unit cells are unusually large ${ }^{16}\left(\sim 10 \AA^{\circ}\right)$. Consequently, the crystal can accommodate foreign molecules generally water as interstitial impurities. ${ }^{1,3,6,16}$ It has been claimed ${ }^{4}$ that prussian blue (ferric ferrocyanide, because $\mathrm{C}$ is linked to $\mathrm{Fe}^{2+}$ as in the ferrocyanide ion) undergoes a linkage isomeric transition at $400^{\circ} \mathrm{C}$ to ferrous ferricyanide where $\mathrm{Fe}^{3+}$ ions are co-ordinated to $\mathrm{C}$ and $\mathrm{Fe}^{2+}$ ions are co-ordinated to N. In this paper we present evidence for the existence of a similar but even more peculiar transition in cupric ferricyanide.

\section{Experimental}

Cupric ferricyanide prepared by double decomposition of a cupric salt with potassium ferrocyanide is a greenish yellow powder of stoichometric composition $\mathrm{Cu}_{3}\left[\mathrm{Fe}(\mathrm{CN})_{6}\right]_{2} \cdot \mathrm{xH}_{2} \mathrm{O}$ (presence of excess $\mathrm{Cu}^{++}$ions ensure that double salts are not formed).

Thermal gravimetric analysis (Figure 1) indicate that $\mathrm{x}$ the maximum number of bonded water molecules is 12 (Figure 1). Cupric ferricyanide and other prussian blue type compounds harbour two kinds of water molecules within the interstices of those co-ordinated to the metal ion $\left(\mathrm{Cu}^{++}\right.$in this case) as well as molecules hydrogen bonded to the co-ordinated ones ${ }^{1.8}$. X-ray structural analysis indicate that generally water molecules do not get bonded to ferro - or ferri - cyanide ions. ${ }^{1,8}$ 


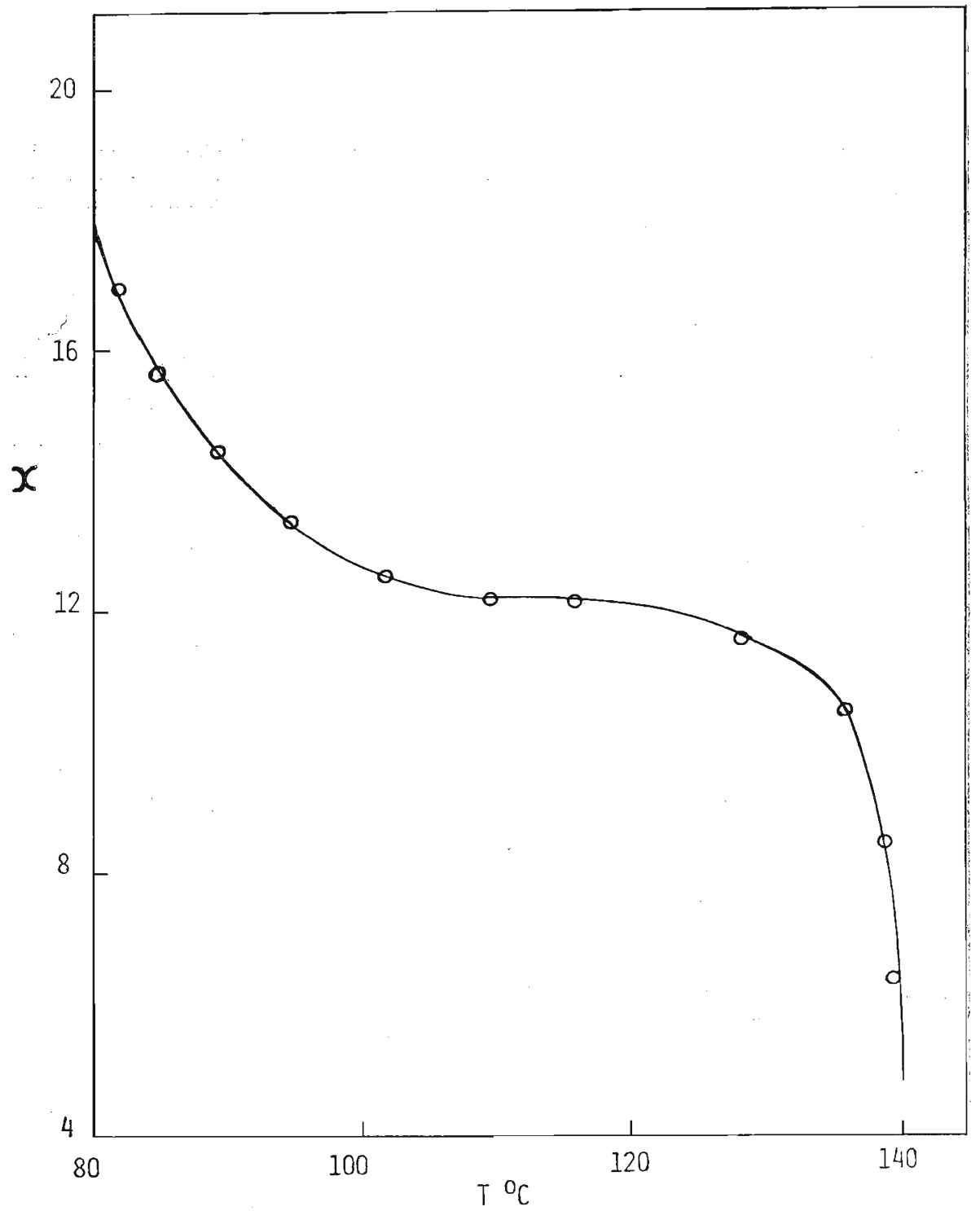

FIGURe 1 - Thermal gravimetric analysis of $\mathrm{Cu}_{3}\left[\mathrm{Fe}(\mathrm{CN})_{6}\right] \cdot \mathrm{xH}_{2} \mathrm{O}$. The plot of $\mathrm{x}$ vs $\mathrm{r}$ when heated at constant rate $2^{\circ} \mathrm{C} \mathrm{min}-1$. 


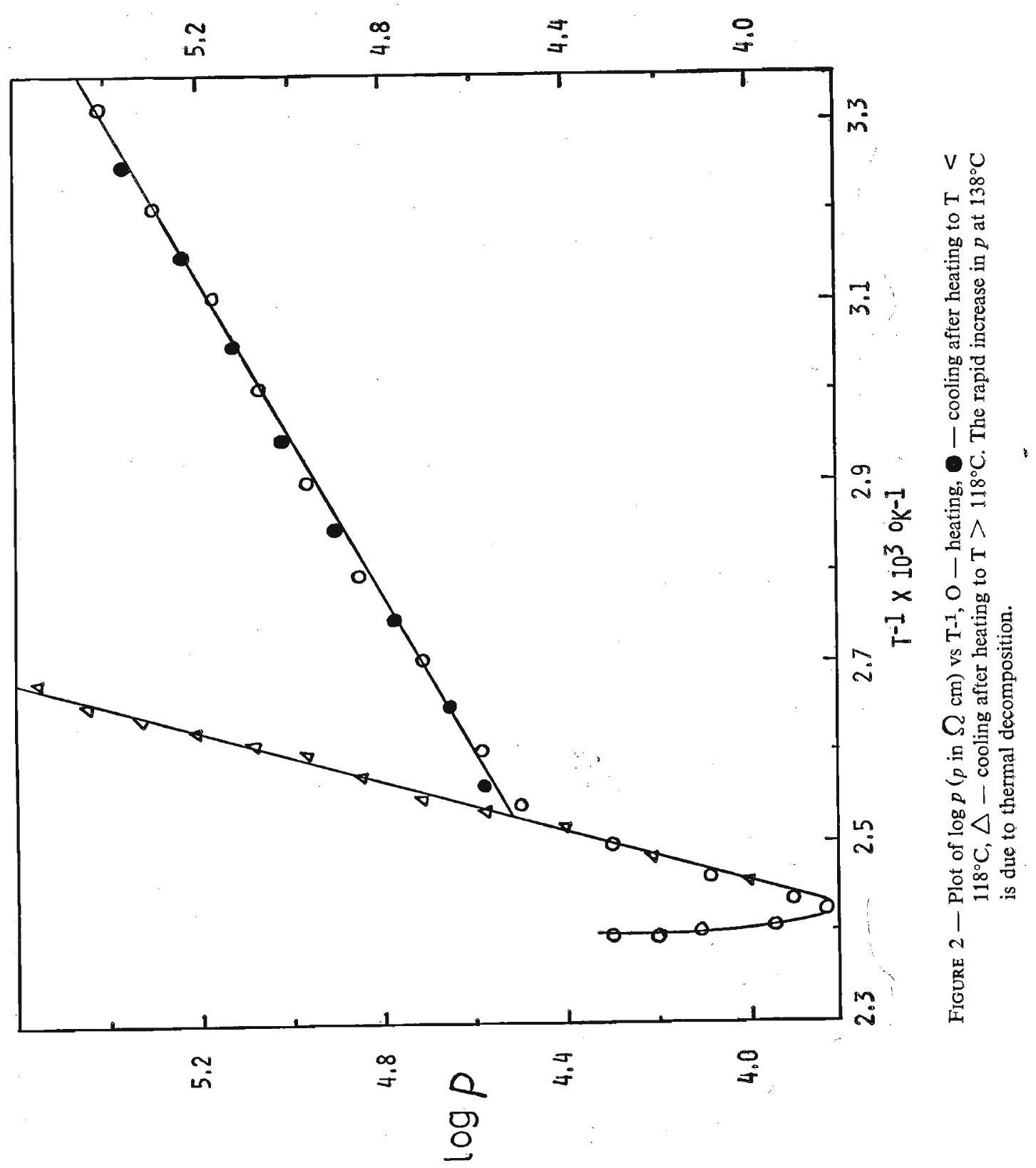


If the interstitial water in cupric ferricyanide is removed by heating the substance up to $118^{\circ} \mathrm{C}$ at atmospheric pressure (Figure 1) or prolonged evacuation of an enclosure containing the material at an elevated temperature below $118^{\circ} \mathrm{C}$, it changes irreversibly into a different form which is black in colour (addition of water does not ehange black form into the green form). The black form bas the same stoichometric composition as the green form and when digested with sodium hydroxide yield the same amount of sodium ferrocyanide as expected from an equal quantity of the green form.

\section{Results and Conclusions}

The author has noted that a large number of hydrated heavy metal ferri ? cyanides exhibit electronic conduction with nearly the same thermal activation energy $(\sim 0.25 \mathrm{eV})$ suggesting that the thermal activation energy of charge carriers is a property largely determined by the ferrocyanide ions in the lattice. ${ }^{11,14}$

Figure 2 gives the plot of $\log \mathrm{p}$ vs $\mathrm{T}^{-1}$ for compressed pellets of cupric ferrocyanide. It is seen that at $118^{\circ} \mathrm{C}$, the thermalactivation energy of charge carriers changes from $0.24 \mathrm{eV}$ a value expected for a ferricyanide to $1.43 \mathrm{eV}$. The change in activation energy is certainly associated with a structural change as there is no eyidence for decomposition, (cupric ferricyanide undergoes thermal decomposition at $139^{\circ} \mathrm{C}$ ). If the sample is cooled after heating to $\mathrm{T} \lesssim 118^{\circ} \mathrm{C}$ p continues to vary with $\mathrm{T}$ along the second path (Figure 2 ). We have also noted that the transition temperature increases with pressure.

Although we are not in a position to give an unambiguous proof, the most likely explanation one could give is that the transition from green to the black form is a linkage isomerism. Since the green form has resulted from neutralization of $\mathrm{Cu}^{++}$and $\mathrm{Fe}(\mathrm{CN})_{6}{ }^{3-}$. ions, the linkage along the edges of unit cubes should be $\mathrm{Fe}^{+++}-\mathrm{CN}-\mathrm{Cu}^{++}$. The bonded water molecules located near $\mathrm{Cu}^{++}$ influence the ligand field stabilization energy as they act as a medium of high dielectric constant that screens the electric field. When water is removed the co-ordination $\mathrm{Fe}^{+++}-\mathrm{CN}-\mathrm{Cu}^{++}$become energetically more favourable. The interesting feature is that there is no unique transition temperature. In a wide range of temperatures the transition occurs if water is removed. It is known that ferrous chromocyanide (brick red) undergoes a linkage transition to chromium ferrocyanide (green) at $100^{\circ} \mathrm{C} .{ }^{9}$ Here there is a well defined transition temperature, the ligand field stabilization favours strong field $\mathrm{C}$ - linkage to $\mathrm{Cr}$ (III). The present example clearly shows the influence of bonded water on ligand field stabilization. 


\section{References}

1. AYRES, J. B. \& WAGGONER W. A. (1971). J. Inorg. Nuclear. Chem. 33, 721.

2. Bonnette, A. K. \& Allen Jr. J. F. (1971). Inorg. Chem. 10, 1613.

3. Cartruad, P., Cointor, A. \& Repand, A. (1961). J. Chem. Soc. Faraday Trans. 1, 77.

4. Cosgrove, J. G., Collins, R. L. \& Murthi, D. S. (1973). J. Am. Chem. Soc. 95, 1083.

5. Flück R, Kerler, W. \& Neuwirth, W. (1963). Angew Chem. Int. Ed. Engl. 2, 277.

6. Ganguly, S. \& Bhattacharya, M. (1983). J. Chem. Soc. Faraday Trans. 1, 79, 1513.

7. Ludi, A. Gudel, H. U. \& RuegG, M. (1970). Inorg. Chem. 9, 2224.

8. Ludi, A. \& Gudel, H. U. (1973). Struct. Bonding 14, 1.

9. Shriver, D. F., Shriver, S. A. \& Anderson, S. E. (1965). Inorg. Chem. 4, 725.

10. Shriver, D. F. \& Brown, D. B. (1969). Inorg. Chem. 8, 42.

11. Tennakone, K. \& Kaluarachchi, D. (1980). Phys. Stat. Sol. (a) 58, K55.

12. Tennakone, K. \& Ariyasinghe, W. M. (1981). J. Chem. Phys. 74 (8), 4461.

13. Tennakone, K. (1983). J. Chem. Phys. 78 (6), 3343.

14. Tennakone, K. (1983). J. Phys. C 16, L1193.

15. Tennakone, K. \& Dharmaratne, W. G. D. (1983). J. Phys. C 16, 5533.

16. Weles, A. F. (1975). Structural Inorganic Chemistry, 4th ed. (Clarendon Press, Oxford). 